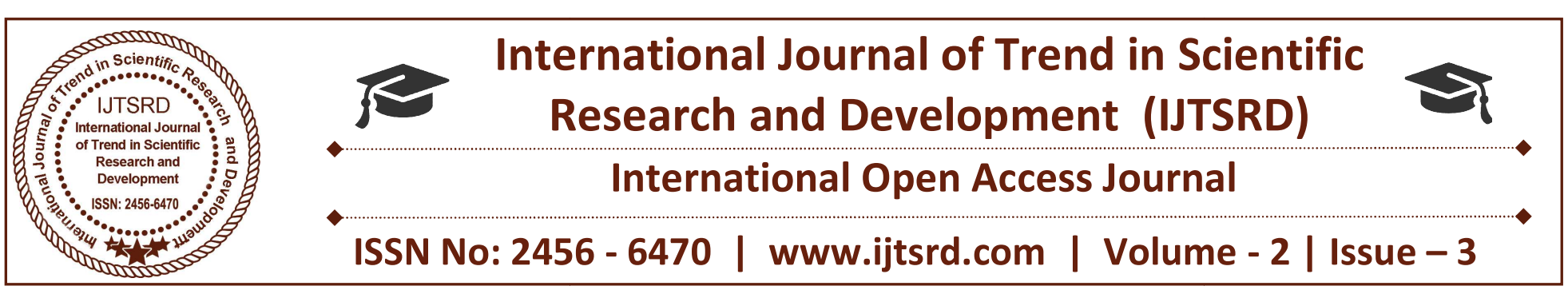

\title{
Agricultural Motor Control and Monitoring
}

\author{
Ashish Gupta, Pradip Maske, Mahesh Lahase \\ Bharati Vidyapeeth College of Engineering, Navi Mumbai, Maharashtra, India
}

\section{ABSTRACT}

Every system is automated in order to face new challenges in the present day situation. Automated systems have less manual operations, so that the flexibility, reliabilities are high and accurate. Hence every field prefers automated control systems. For utilization of appliances, the new concept has been thought to manage them remotely by using GSM, which enables the user to control switching ON/OFF of agricultural motor remotely. Just by dialing keypad of remote phone, from where we are calling we can perform ON / OFF operation of the motor. This system also operates by sending and receiving SMS. The main aim of this project is to turn on and off water pump from anywhere using mobile phone and also automatic control of motor using various sensors. Soil moisture sensor is used to measure the amount of moisture content present in the soil and stop motor pump at particular level, Humidity Sensor is used to monitor whether the level of humidity in environment is high or low, Rain Sensor is used to detect the rain in field and stop the pump if there is rain and the water level is continuously monitor the level and at particular level motor is turned OFF. If we send a message to the system, it will send a reply with the status of all the sensors by using GSM technology.

Keywords: Arduino, Soil Moisture Sensor, Level Sensor, Rain Sensor, Humidity sensor, GSM modem Motor Driver, Motor Pump

\section{INTRODUCTION}

In present days, in the field of agriculture farmers are facing major problems in watering their crops. It's because they don't have proper idea about the availability of the power. Even if it is available, they need to pump water and wait until the field is properly watered, which compels them to stop doing other activities - which are also important for them, and thus they loss their precious time and efforts. But, there is a solution - an Agricultural motor control And monitoring not only helps farmers but also others for watering their gardens as well.

The main aim of this project is to turn on and off water pump from anywhere using mobile phone. Now a day's most of the farmers use water from the wells and underground water resources for their farms. And for this they need water pumps. Using Arduino, GSM module \& sensors we are implementing this project. The purpose of this is to help the farmer to turn on or turn off the motor. By using this farmer is able to operate the motor from anywhere using mobile phone.

\section{RELATED WORK}

Real-Time Atomization of Agricultural Environment for Social Modernization of Indian Agricultural System focuses on using an ATmega328 microcontroller, GSM services which operate through SMS as a link between controller and centralized unit. GSM is used to inform the user about exact field condition through a SMS on user request. The GSM model is controlled by a standard set of AT (Attention) commands. The system continuously monitors the soil moisture, water level, Rain, humidity and provides the details about the field to user though SMS. The system consists of a centralized unit having a subscriber number which forms a link between user and device and acts as a primary node for sending and receiving the data though SMSs by the user. The centralized unit communicates with the system through SMSs which will be received by GSM with the help of SIM card; the GSM sends this data to controller, after processing it displays it on the LCD. 


\section{METHODOLOGY}

BLOCK DIAGRAM

\section{Transmitter Section}

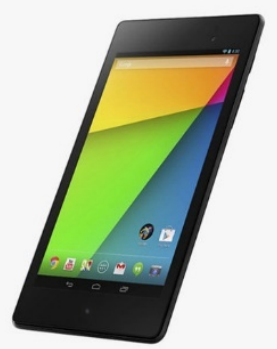

\section{Receiver section}

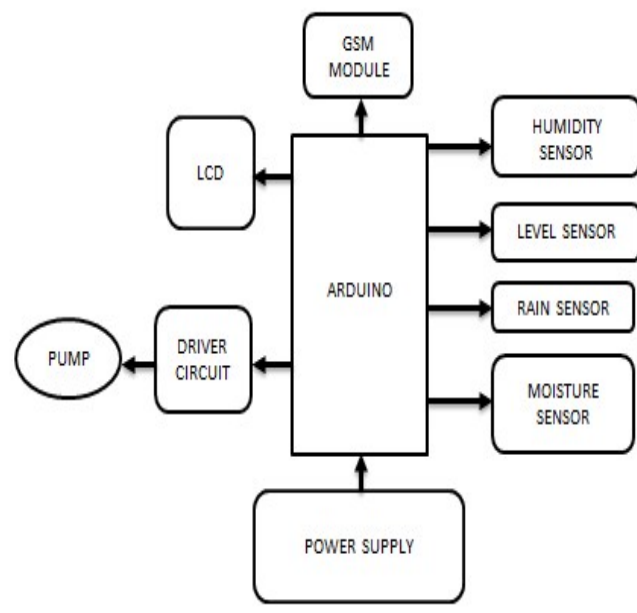

\section{FLOW CHART}

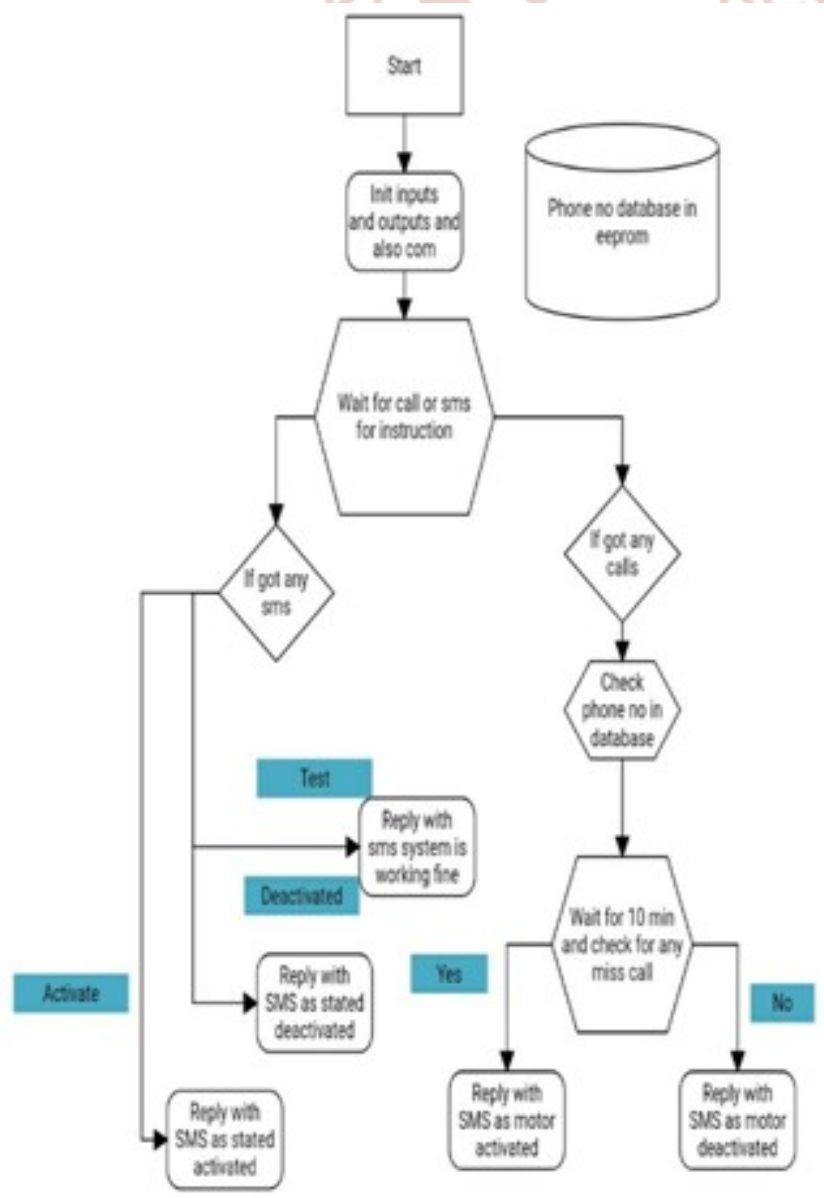

\section{B. Hardware description}

\section{ARDUINO UNO}

Arduino is an open source electronics prototyping platform. It can be sense the environment by receiving input from man sensors and using this data it can be control motor, light etc.

The microcontroller is present on the board is programmed using the Arduino programming language (based on Wiring) and the Arduino development environment (based on Processing.

Arduino boards can be built by hand or purchased preassembled; the software can be downloaded for free. The hardware reference designs (CAD files) are available under an open-source license, you are free to adapt them to your needs.

Arduino hardware programming done using a Wiringbased language (syntax + libraries), similar to $\mathrm{C}++$.

\section{GSM MODULE}

GSM modem is a modem which accepts a SIM card. From the mobile operator perspective, a GSM modem looks just like a mobile phone.

\section{HUMIDITY SENSOR}

Humidity is the presence of water in air. The amount of water vapor in air can affect human comfort and many manufacturing processes in industries. The presence of water vapor also influences various physical, chemical, and biological processes.

Controlling or monitoring humidity is very important in many industrial \& domestic applications. In many industry, humidity or moisture levels needs to be properly controlled \& monitored. In medical applications, humidity control is required for respiratory equipments, sterilizers, incubators, pharmaceutical processing, and biological products. Humidity control is also necessary in chemical gas purification, dryers, ovens, film desiccation, paper and textile production in such many more applications. In agriculture, measurement of humidity is important for plantation protection (dew prevention), soil moisture monitoring, etc. In all such applications, humidity sensors are employed to provide an indication of the moisture levels in the environment. 


\section{MOISTURE SENSOR}

Soil moisture sensors measure the water content in soil. Since the direct gravimetric measurement of free soil moisture requires removing, drying, and weighting of a sample, soil moisture sensors measure the volumetric water content indirectly by using some other property of the soil, such as electrical resistance, dielectric constant, or interaction with neutrons, as a proxy for the moisture content. The relation between the measured property and soil moisture must be calibrated and may vary depending on environmental factors such as soil type, temperature, or electric conductivity. Reflected microwave radiation is affected by the soil moisture and is used for remote sensing in hydrology and agriculture. Portable probe instruments can be used by farmers or gardeners.

\section{LEVEL SENSOR}

The sensing probe element consists of a special wire cable which is capable of accurately sensing the surface level of nearly any fluid, including water, salt water and oils. The sensor element is electrically insulated and isolated from the liquid into which it is inserted, and will not corrode over time. Unlike, other sensors, the measurement range is adjustable from a few centimeters to over several meters. The reading is reported back as an analog voltage ranging from $0 \mathrm{~V}$ to $3 \mathrm{~V}$ where $0 \mathrm{~V}$ represents the sensor not being submersed, and $3 \mathrm{~V}$ represents the maximum water level.

\section{RAIN SENSOR}

A rain sensor is a switching device activated by rainfall. There is main applications for rain sensors. The first is at the time of rainfall automatic irrigation system is shut down. An additional application in professional satellite communications antennas is to trigger a rain blower on the aperture of the antenna feed, to remove water droplets from the mylar cover that keeps pressurized and dry air inside the waveguides.

\section{EXPERIMENTAL RESULT}

In this project we control status of motor that is ON/OFF using simply mobile, Arduino, GMS operations and also monitoring this status using various sensors, that is (level, moisture, rain, humidity sensors).

\section{CONCLUSION}

In this paper we have concluded, there is an urgent need for a system that makes the agricultural process easier and burden free from the farmer's side. With the recent advancement of technology it has become necessary to increase the annual crop production output of our country India, an entirely agro centric economy. The ability to conserve the natural resources as well as giving a splendid boost to the production of the crops is one of the main aims of incorporating such technology into the agricultural domain of the country. To save farmer's effort, water and time has been the most important consideration. Hence systems need to be designed to provide this ability efficiently using wireless sensor networking, sprinkler irrigation, GSM, SMS technology.

\section{REFRENCES}

1. https://www.slideshare.net/DishaModil/automati c-intelligent-plant-irrigation-system-using-gsmand-arduino-board

2. https://www.homemade-circuits.com/gsm-pumpmotor-controller-circuit-using/arduino

3. hittp://www.circuitstoday.com/interface-gsmmodule-with- arduino

4. KamrulHassan,Raziul Islam Siddiqui,Md. Takdirul Islam, NahidAlam Siddique," GSM Based Atomatic Motor Control and Protection System",IJART Volume-2, Feb 2013.

5. VenkataNarayanaEluri, K.Madhusudhana Rao, A. Srinag, "Wireless Solution for Water Saving.

6. Agriculture Using Embedded System",IJCSBI, Volume 2, June 2013.

7. S.Sumeetha, [7] Ejio for Virginia Ebere and OladipoOnaolapo Francisca, "Microcontroller based Automatic Water level Control System", NnamdiAzikiwe University, International Journal of Innovative Research in Computer and Communication Engineering Vol. 1, Issue 6, August 2013. 